\title{
Infection prevention bundle reduces surgical site infections following cranial surgery
}

\author{
Beuy Joob ${ }^{1} \cdot$ Viroj Wiwanitkit ${ }^{2}$
}

Received: 28 November 2018 / Accepted: 18 December 2018 / Published online: 7 January 2019

(C) Springer-Verlag GmbH Austria, part of Springer Nature 2019

Dear Editor, we read the publication on "The implementation of an infection prevention bundle reduces surgical site infection (SSI) s following cranial surgery" with a great interest [3]. Jörger et al. concluded that "The implementation of a bundle of five basic infection prevention steps leads to a clinical relevant reduction of SSIs [3]." In fact, SSI is an important problem in clinical practice and there should be a good preventive measure against the problem. The implementation of guideline/protocol aiming at prevention of the problem is interesting. Indeed, the instruction according to the guideline/ protocol is usually good; however, the important concern is the practice of the practitioner. Most of the problem in clinical practice is usually due to human error [1]. In a recent report from the USA, the non-compliance of practitioners towards infection control guideline for SSI prevention is not uncommon, and the SSI problem can be due to the contamination during pre-, intra-, or post- operative phase [2]. Any tools against SSI will be useless if we do not start with promotion of the responsibility of the practitioner.

This article is part of the Topical Collection on Infection

Beuy Joob

beuyjoob@hotmail.com

Sanitation 1 Medical Academic Center, Bangkok, Thailand

2 Dr DY Patil University, Pune, India

\section{Compliance with ethical standards}

Conflict of interest The authors declare that they have no conflict of interest.

\section{References}

1. Backman LA, Carusillo E, D'aquila LN, Melchreit R, Fekieta R (2017) Validation of surgical site infection surveillance data in colon procedures reported to the Connecticut Department of Public Health. Am J Infect Control 45(6):690-691

2. Davis CH, Kao LS, Fleming JB, Aloia TA, Texas Alliance for Surgical Quality Collaborative (2017) Multi-institution analysis of infection control practices identifies the subset associated with best surgical site infection performance: a Texas alliance for surgical quality collaborative project. J Am Coll Surg

3. Jörger AK, Wimmer N, Lange N, Wagner A, Janssen I, Krieg S, Meyer B, Shiban E (2018) The implementation of an infection prevention bundle reduces surgical site infections following cranial surgery. Acta Neurochir 160(12):2307-2312

\section{Publisher's note}

Springer Nature remains neutral with regard to jurisdictional claims in published maps and institutional affiliations. 